\title{
Eficácia de Fusarium spp. no controle da murcha-de-curtobacterium do feijoeiro
}

\author{
Rafael Moreira Soares ${ }^{1 *}$ e Antonio Carlos Maringoni ${ }^{2}$
}

${ }^{1}$ Embrapa Soja, Rodovia Carlos João Strass - Distrito da Warta, 86001-970 Londrina, PR, Brasil

${ }^{2}$ Faculdade de Ciências Agronômicas, FCA/UNESP, Rua José Barbosa de Barros no 1780, 18610-307 Botucatu, SP, Brasil. *Parte da tese de doutorado do primeiro autor apresentada à FCA/UNESP.

Autor para correspondência: Rafael Moreira Soares (rafael.soares@embrapa.br)

Data de chegada: 25/08/2016. Aceito para publicação em: 07/08/2017

$10.1590 / 0100-5405 / 168402$

\section{RESUMO}

Soares, R.M.; Antonio Carlos Maringoni, A.C. Eficácia de Fusarium spp. no controle da murcha-de-curtobacterium do feijoeiro. Summa Phytopathologica, v.44, n.1, p.79-82, 2018.

O presente trabalho teve como objetivos avaliar a ação inibitória de Fusarium oxysporum f. sp. phaseoli e Fusarium spp. in vitro sobre isolados de Curtobacterium flaccumfaciens pv. flaccumfaciens (Cff) e ação de Fusarium spp. no controle da murcha-de-curtobacteriurn, em plantas de feijoeiro cultivar IAC Carioca, conduzidas em vaso com substrato infestado pelo fungo em quatro concentrações. Os isolados de F. oxysporum f. sp. phaseoli e Fusarium spp. cultivados sobre discos de papel-de-filtro em meio de cultura agarizado produziram metabólitos que inibiram o crescimento dos isolados de Cff. Porém, extratos obtidos por filtragem de cultivos dos isolados fúngicos em meio líquido não inibiram, in vitro, o crescimento dos isolados de Cff. Os isolados de Fusarium spp. infestados no substrato, independente da concentração utilizada, não foram eficazes no controle da murcha-de-curtobacterium nas plantas de feijoeiro.

Palavras-chave: Curtobacterium flaccumfaciens pv.flaccumfaciens, controle biológico, Phaseolus vulgaris, indução de resistência.

\section{ABSTRACT}

Soares, R.M.; Antonio Carlos Maringoni, A.C. Effectiveness of Fusarium spp. in controlling bacterial wilt in beans. Summa Phytopathologica, v.44, n.1, p.79-82, 2018.

This study aimed to evaluate the inhibitory action of Fusarium oxysporum f. sp. phaseoli and Fusarium spp., in vitro, on isolates of Curtobacterium flaccumfaciens pv. flaccumfaciens (Cff) and the action of Fusarium spp. in controlling bacterial wilt in bean plants, cultivar IAC Carioca, grown in pots with substrate infested by the fungus at four concentrations. Isolates of $F$. oxysporum $\mathrm{f}$. sp. phaseoli and Fusarium spp. grown on paper filter discs, in agar culture medium, produced metabolites that inhibited the growth of Cff isolates. However, extracts obtained by filtering the cultures of fungal isolates in liquid medium did not inhibit, in vitro, the growth of Cff isolates. The isolates of Fusarium spp. infested in the substrate, regardless of the used concentration, were not effective in controlling bacterial wilt in bean plants.

Keywords: Curtobacterium flaccumfaciens pv. flaccumfaciens, biological control, Phaseolus vulgaris, resistance induction.

Curtobacterium flaccumfaciens pv. flaccumfaciens (Cff) é o agente causal da doença denominada murcha-de-curtobacterium, que ocorre com frequencia na cultura do feijoeiro, em várias localidades do Brasil e causa danos à cultura (16). A doença é caracterizada pelo subdesenvolvimento, amarelecimento, murcha, seca e queda de folhas, que pode levar à morte das plantas. É de difícil controle e o manejo dessa doença restringe-se à utilização de cultivares resistentes, além de rotação de culturas e o uso de sementes sadias. Alguns trabalhos de pesquisa têm evidenciado a potencialidade de controle dessa doença com a microbiolização de sementes com agentes de biocontrole, principalmente isolados bacterianos selecionados para esse fim, tais como: Pantoea aglomerans, Rhizobium leguminosarum (7), Bacillus subtilis (11), Bacillus cereus e Pseudomonas fluorescens (4).

Fungos do gênero Fusarium, além de causarem doenças a muitas plantas de interesse agrícola, também têm demonstrado potencialidade de atuarem como agentes antagônicos a patógenos fúngicos e bacterianos, como por exemplo Fusarium moniliforme (8), F. solani (15) e F. proliferatum (14).

Fusarium spp. produzem diversas substâncias que podem ter efeito tóxico a outros organismos vivos, entre elas micotoxinas, fitotoxinas, antibióticos, pigmentos, enzimas e reguladores de crescimento (12). Toxinas como licomarasmina, ácido fusárico, zearalenona, fusarina, moniliformina e outras tem sido objeto de pesquisa para avaliar seus efeitos na planta e na capacidade de controlarem bactérias e fungos $(5 ; 12)$.

Baker et al. (3), estudando a atividade antimicrobiana de nafioquinonas obtidos, ou derivados sinteticamente de extratos de culturas de $F$. solani e $F$. oxysporum, observaram a inibição de $C$. flaccumfaciens pv. poinseitiae por seis dos 11 compostos avaliados.

$\mathrm{Na}$ interação entre patógenos causadores de murcha, Clavibacter michiganensis subsp. insidiosus e $F$ oxysporum f. sp. medicaginis, em alfafa, foi constatada menor severidade dos sintomas da murcha bacteriana em plantas inoculadas com a mistura dos dois patógenos, do que em plantas inoculadas com a bactéria isoladamente. F. oxysporum f. sp. medicaginis produziu substâncias que inibiram $C$. michiganensis subsp. insidiosus $(6 ; 9)$. Foi também observado que $F$. verticillioides $(=$ F. moniliforme) competiu com Bacillus mojavensis, agente endonfítico de controle biológico em milho, por nichos de colonização na planta, 
pela produção de ácido fusárico que foi tóxico ao agente de biocontrole (2).

Baseado nesses fatos, este trabalho teve como objetivo avaliar se isolados de F. oxysporum f. sp. phaseoli e Fusarium spp., obtidos de plantas de feijoeiro, produzem substâncias inibitórias in vitro a Cff e se eles possuem ação in vivo no controle da murcha-de-curtobacterium do feijoeiro.

\section{MATERIAL E MÉTODOS}

Produção de substâncias in vitro por F. oxysporum f. sp.phaseoli inibitórias a $C$. flaccumfaciens pv. flaccumfaciens

Para este experimento foi usada a metodologia descrita por Johnson et al. (9), com adaptações, e dois isolados de F. oxysporum f. sp. phaseoli patogênicos ao feijoeiro (Feij 2626 e Feij 2627), conforme constatado em testes de patogenicidade anteriores (dados não publicados).

Discos de meio de cultura nutriente-sacarose-ágar (NSA) (3g extrato de carne, $5 \mathrm{~g}$ peptona bacteriológica, $10 \mathrm{~g}$ sacarose, $15 \mathrm{~g}$ ágar bacteriológico, 1L água destilada), contendo crescimento miceliano, foram repicados para o centro de placas de Petri contendo meio NSA e ao redor destes foram depositados discos de papel-de-filtro esterilizados de 1,3 cm de diâmetro. Após a incubação por 7 dias, a $28^{\circ} \mathrm{C}$, no escuro, os discos de papel-de-filtro contendo crescimentos fúngicos foram removidos e transferidos para um dessecador que continha um recipiente de vidro com $20 \mathrm{~mL}$ de clorofórmio. $\mathrm{O}$ dessecador permaneceu tampado por $12 \mathrm{~h}$, em condições de laboratório, com a finalidade de inativar as estruturas fúngicas. Discos de papel-de-filtro esterilizados, sem crescimento fúngico, foram submetidos a esse tratamento e serviram de controle.

Os isolados Feij 2716, Feij 2718, Feij 2719, Feij 2720 e Feij 2721 de Cff foram previamente cultivados em $50 \mathrm{~mL}$ de nutriente líquido (NL) (3g extrato de carne, $5 \mathrm{~g}$ peptona bacteriológica, $1 \mathrm{~L}$ água destilada), durante $48 \mathrm{~h}$, a $28^{\circ} \mathrm{C}$. Seguida a incubação, as suspensões dos isolados bacterianos foram transferidas individualmente para recipientes contendo meio de cultura NSA autoclavado fundente, a $45-50^{\circ} \mathrm{C}$, na proporção 1:9 (suspensão bacteriana: meio de cultura).

Essa mistura foi transferida para placas de Petri e após a solidificação foi colocado no centro de cada placa um disco de papel-de-filtro contendo crescimento fúngico inativado ou disco de papel-de-filtro sem crescimento fúngico. O delineamento experimental empregado foi o inteiramente casualizado, no esquema fatorial 2 x 5, sendo dois isolados fúngicos e cinco isolados de Cff. Foram feitas cinco repetições, sendo cada uma representada por uma placa de Petri.

Após essa operação, as placas foram submetidas à refrigeração ( \pm $5^{\circ} \mathrm{C}$ ) por $1,5 \mathrm{~h}$, com a finalidade da difusão dos metabólitos fúngicos contidos no disco de papel-de-filtro para o meio de cultura. As placas foram incubadas a $28^{\circ} \mathrm{C}$, por 48 horas, e a seguir aferidos, em $\mathrm{mm}$, os diâmetros perpendiculares dos halos de inibição formados ao redor dos discos de papel-de-filtro.

Produção de substâncias in vitro por isolados de Fusarium spp. inibitórias a $C$. flaccumfaciens pv. flaccumfaciens

Este ensaio foi conduzido de forma semelhante ao anterior. Foram empregados três isolados de Fusarium spp. não patogênicos ao feijoeiro (Feij 2706, Feij 2707 e Feij 2708), conforme constatado em testes de patogenicidade anteriores (dados não publicados), e os isolados Feij 2716 e Feij 2720 de Cff.
O delineamento experimental empregado foi o inteiramente casualizado, no esquema fatorial $3 \times 2$, sendo três isolados fúngicos e dois isolados de Cff. Para cada tratamento foram feitas cinco repetições, sendo cada uma representada por uma placa de Petri.

Produção de substâncias in vitro por isolados de Fusarium spp. e F. oxysporum f. sp. phaseoli cultivados em meio de cultura líquido inibitórias a $C$. flaccumfaciens pv. flaccumfaciens

Foram utilizados dois isolados patogênicos de $F$. oxysporum $\mathrm{f}$. sp. phaseoli (Feij 2626 e Feij 2627) e três isolados não patogênicos de Fusarium ssp. (Feij 2706, Feij 2707 e Feij 2708), conforme constatado em testes de patogenicidade anteriores (dados não publicados)

Discos de micélio de $0,5 \mathrm{~cm}$ de diâmetro dos isolados fúngicos foram transferidos separadamente para erlenmeyer contendo 250 $\mathrm{mL}$ de meio líquido NS (3,0 g extrato de carne, 5,0 g peptona, 5,0 $\mathrm{g}$ sacarose, 1,0 L de água destilada).

Dois ensaios foram instalados simultaneamente, com os isolados fúngicos incubados com ou sem agitação. Os frascos foram incubados durante 10 dias em agitador de bancada $(120 \mathrm{rpm} / \mathrm{min})$, sob temperatura ambiente $\left(25 \pm 2^{\circ} \mathrm{C}\right)$, ou sem agitação, em estufa, a $28^{\circ} \mathrm{C}$, no escuro.

Após a incubação, as suspensões formadas no meio de cultura líquido foram filtradas, em camada dupla de gaze, e centrifugadas a $8.000 \mathrm{~g}$, durante 20 minutos. Os sobrenadantes resultantes foram filtrados em filtro bacteriológico. Obtiveram-se cerca de $30 \mathrm{~mL}$ de extrato líquido de cada isolado fúngico, sendo metade autoclavado. Em seguida, alíquotas de $15 \mathrm{~mL}$ de cada extrato líquido foram autoclavadas a $121^{\circ} \mathrm{C}$, por 30 minutos.

Posteriormente, foram colocados discos de papel de filtro esterilizado no centro de placas de Petri contendo meio de cultura NSA com suspensões bacterianas dos isolados de Cff (Feij 2716 e Feij 2720), conforme descrito no ensaio anterior. Sobre cada disco de papel-de-filtro foram depositados $30 \mu \mathrm{L}$ de cada extrato líquido dos isolados fúngicos autoclavados ou não.

Após essa operação, as placas foram refrigeradas $\left( \pm 5^{\circ} \mathrm{C}\right)$ por 1 hora e meia, visando a difusão dos metabólitos fúngicos para o meio de cultura. A seguir, as placas foram incubadas a $28^{\circ} \mathrm{C}$, durante 48 horas, e realizada a aferição, em mm, dos diâmetros perpendiculares dos halos de inibição formados.

$\mathrm{O}$ delineamento experimental utilizado em cada ensaio foi o inteiramente casualizado, no esquema fatorial $5 \times 2$, sendo cinco isolados fúngicos e dois modos de incubação. Foram feitas cinco repetições (uma placa de Petri/repetição) para cada tratamento.

Avaliação de isolados de Fusarium spp. no controle da murcha-de-curtobacterium

Dois discos de meio de cultura de $0,6 \mathrm{~cm}$ de diâmetro, contendo crescimento fúngico (isolados Feij 2706 e Feij 2707) foram transferidos para erlenmeyers contendo $500 \mathrm{~mL}$ de meio líquido de Armstrong (13) e incubados por sete dias, sem agitação, à temperatura de $26 \pm 2^{\circ} \mathrm{C}$, no escuro. Posteriormente, as suspensões contendo os crescimentos fúngicos foram homogeneizadas, por 30 segundos, em liquidificador. Em seguida, foram feitas as diluições das suspensões nas proporções de 1:10, 1:50, 1:100 e 1:500 (v/v) em água destilada.

A infestação com os isolados fúngicos foi feita vertendo-se 200 $\mathrm{mL}$ das suspensões fúngicas obtidas ou água destilada (testemunha) em vasos de $2 \mathrm{~L}$ de capacidade contendo substrato autoclavado, 
constituído de $70 \%$ de areia grossa, $15 \%$ de terra e $15 \%$ de esterco de curral curtido. Em seguida, realizou-se o plantio de cinco sementes pré-geminadas de feijoeiro cultivar IAC Carioca. Após oito dias da emergência, foram deixadas três plântulas em cada vaso e as mesmas foram inoculadas com o isolado de Cff (Feij 2721), por duas punções em cada caule, entre as folhas cotiledonares e as folhas primárias com agulha entomológica umedecida em colônia bacteriana $(4 ; 10)$.

A avaliação dos sintomas da doença foi realizada aos 15,20 e 25 dias após a inoculação, atribuindo-se notas de severidade que variam de 1 a 9, conforme Maringoni (10).

O delineamento experimental empregado foi o de blocos ao acaso com nove tratamentos e quatro repetições. Cada parcela experimental foi representada por um vaso.

\section{RESULTADOS E DISCUSSÃO}

Conforme apresentado na Tabela 1 , os dois isolados de F. oxysporum f. sp. phaseoli produziram metabólitos in vitro que foram capazes de inibir crescimento dos cinco isolados de Cff. Os isolados Feij 2716 e Feij 2720 de Cff foram os mais inibidos, pois formaram os maiores halos de inibição, quando comparado com os outros isolados avaliados.

Tabela 1. Sensibilidade in vitro de isolados de Curtobacterium flaccumfaciens pv. flaccumfaciens (Cff) a metabólitos produzidos por Fusarium oxysporum f. sp. phaseoli (Fop). Diâmetro médio (mm) do halo de inibição.

\begin{tabular}{cccc}
\hline \multirow{2}{*}{ Isolado de Cff } & \multicolumn{2}{c}{ Isolado de Fop } & \multirow{2}{*}{ Média } \\
\cline { 2 - 3 } & Feij 2625 & Feij 2627 & \\
\hline Feij 2716 & 5,10 & 8,60 & $6,85 \mathrm{ab}^{*}$ \\
Feij 2718 & 3,60 & 3,90 & $3,75 \mathrm{bc}$ \\
Feij 2719 & 4,00 & 6,20 & $5,10 \mathrm{c}$ \\
Feij 2720 & 6,60 & 9,60 & $8,10 \mathrm{a}$ \\
Feij 2721 & 3,80 & 4,80 & $4,30 \mathrm{c}$ \\
\hline Média & $4,62 \mathrm{~B}$ & $6,62 \mathrm{~A}$ & \\
\hline
\end{tabular}

*Medias seguidas de mesmas letras minúscula na coluna ou maiúscula na linha, não diferem entre si, pelo teste de Tukey a 5\% de probabilidade.

Os resultados obtidos neste ensaio concordam com aqueles descritos por Johonson et al. (9) para F. oxysporum f. sp. medicaginis e Clavibacter michiganensis subsp. insidiosum, patógenos causadores de murcha em alfafa.

Apenas dois dos três isolados de Fusarium spp. (Feij 2706 e Feij 2707), não patogêncios ao feijoeiro, produziram metabólitos in vitro que interferiram no crescimento dos dois isolados de Cff (Tabela 2). Houve diferença na sensibilidade dos isolados de Cff aos metabólitos produzidos pelos isolados de Fusarium spp. e o mais sensível foi o Feij 2720.

É de conhecimento a produção de metabólitos tóxicos por Fusarium spp. (antibióticos, enzimas extracelulares, fitotoxinas, micotoxinas, pigmentos e reguladores de crescimento) que estão relacionados à patogênese em vegetal (12) e também à produção de substâncias que interferem no crescimento de bactérias e fungos in vitro ou in vivo $(2 ; 8 ; 14 ; 15)$.

Não foi constatada a produção de metabólitos tóxicos pelos isolados de Fusarium spp. e F. oxysporum f. sp. phaseoli, sob cultivo em meio de cultura líquido com ou sem agitação, independente da autoclavagem do líquido colhido após o cultivo dos isolados
Tabela 2. Sensibilidade in vitro de isolados de Curtobacterium flaccumfaciens pv. flaccumfaciens (Cff) a metabólitos produzidos por Fusarium spp. Diâmetro médio (mm) do halo de inibição formado.

\begin{tabular}{lcccc}
\hline \multirow{2}{*}{ Isolado de Cff } & \multicolumn{3}{c}{ Isolado Fusarium spp. } & \multirow{2}{*}{ Média } \\
\cline { 2 - 4 } & Feij 2706 & Feij 2707 & Feij 2708* & \\
\hline Feij 2716 & 5,50 & 5,50 & 0 & $5,50 \mathrm{~b} * *$ \\
Feij 2720 & 7,30 & 6,50 & 0 & $6,90 \mathrm{a}$ \\
\hline Média & $6,4 \mathrm{~A}$ & $6,0 \mathrm{~A}$ & & \\
\hline
\end{tabular}

*Não submetidos à análise estatística.

**Medias seguidas de mesmas letras minúscula na coluna ou maiúscula na linha, não diferem entre si, pelo teste de Tukey a 5\% de probabilidade.

fúngicos, que foram inibitórios aos isolados de Cff.

Constatou-se diferenças quanto aos aspectos do desenvolvimento das culturas fúngicas, pois, na presença da agitação, o meio de cultura líquido tinha a coloração arroxeada e no cultivo sem agitação, o meio de cultura tinha coloração esbranquiçada, com uma densa camada micelial branca na sua superfície.

Normalmente, os metabólitos de Fusarium spp. são obtidos em meio de cultura líquido, com posterior purificação ou não, para serem avaliados in vitro sobre fungos e bactérias. A produção de fusariocina C por F. moniliforme foi obtida por Itô (8) sob o cultivo do fungo em meio líquido de Adyes, durante sete dias, a $25^{\circ} \mathrm{C}$, com agitação.

Para a produção de ácido fusárico por $F$. verticilloides, Bacon et al. (2) cultivaram o fungo em meio sintético líquido, a $28^{\circ} \mathrm{C}$, sob agitação, durante 15 dias. Conforme Tayung et al. (15), para a produção de metabólitos por $F$. solani com atividade antimicrobiana, o fungo foi cultivado em meio líquido batata-dextrose (BD), a $24 \pm 2^{\circ} \mathrm{C}$, sob agitação, por 15 dias. Já Rasekhi et al. (14) obtiveram compostos antimicrobianos produzidos por $F$. proliferatum, cepa FP85, sob o cultivo do fungo em meio líquido BD, a $28^{\circ} \mathrm{C}$, durante 21 dias. Em contrapartida, isolados de F. oxysporum f.sp. medicaginis só produziram metabólitos tóxicos a $C$. michiganensis subsp. insidiosum em cultivo sem agitação, no meio de cultura NL, incubado por quatro dias, e essas substâncias foram termolábeis, degradadas pela autoclavagem durante $20 \mathrm{~min}$ (9).

De acordo com Tayung et al. (15), alguns fatores influenciam a produção de metabólitos antimicrobianos por $F$. solani, tais como $\mathrm{pH}$ do meio de cultura, temperatura e período de incubação. Temperatura de incubação a $30 \pm 1^{\circ} \mathrm{C}$, meio de cultura $\mathrm{BD}$ líquido ligeiramente ácido ( $\mathrm{pH}$ 6) e incubação por 10 dias foram os melhores parâmetros.

Com relação ao controle da murcha-de-curtobacterium pelos isolados de Fusarium spp., cujas suspensões do cultivo em meio de cultura líquido Armstrong, contendo os prováveis metabólitos tóxicos e as estruturas fúngicas empregadas na infestação dos substrato, nas diferentes concentrações, não apresentaram eficácia no controle da doença. As plantas de feijoeiro IAC Carioca apresentaram elevados valores de severidade, semelhante ao tratamento testemunha (Tabela 3). Frosheiser e Barnes (6) e Johnson et al. (9) observaram que $F$. oxysporum f. sp. medicaginis, quando inoculado juntamente com C. michiganensis subsp. michiganensis, interferiu na colonização da bactéria em plantas de alfafa. Em plantas de milho, Bacon et al. (2) constataram que $F$. verticillioides competiu com Bacillus mojavensis, pela produção de ácido fusárico, que reduziu a colonização do agente de biocontrole e interferiu no controle biológico. Os resultados aqui relatados para Fusarium spp. e Cff não evidenciaram tal fato (Tabela 3 ). 
Tabela 3. Avaliação dos sintomas de murcha-de-curtobacterium em plantas de feijoeiro, cultivar IAC Carioca, cultivadas em substrato inoculado com diferentes concentrações de isolados de Fusarium spp.

\begin{tabular}{ccccc}
\hline $\begin{array}{c}\text { Isolado de } \\
\text { Fusarium spp. }\end{array}$ & $\begin{array}{c}\text { Concentração } \\
(\mathbf{v} / \mathbf{v})\end{array}$ & \multicolumn{2}{c}{ Dias após a inoculação } \\
& & & & \\
\cline { 2 - 5 } & $1: 10$ & $3,67^{*}$ a** & 7,17 a & $7,67 \mathrm{a}$ \\
\hline Feij 2706 & $1: 50$ & $3,34 \mathrm{a}$ & $7,17 \mathrm{a}$ & $7,50 \mathrm{a}$ \\
& $1: 100$ & $3,00 \mathrm{a}$ & $7,00 \mathrm{a}$ & $7,34 \mathrm{a}$ \\
& $1: 500$ & $3,00 \mathrm{a}$ & $7,00 \mathrm{a}$ & $7,34 \mathrm{a}$ \\
Feij 2707 & $1: 10$ & $2,67 \mathrm{a}$ & $6,00 \mathrm{a}$ & $7,33 \mathrm{a}$ \\
& $1: 50$ & $2,67 \mathrm{a}$ & $5,77 \mathrm{a}$ & $7,17 \mathrm{a}$ \\
& $1: 100$ & $2,33 \mathrm{a}$ & $5,50 \mathrm{a}$ & $7,17 \mathrm{a}$ \\
& $1: 500$ & $2,33 \mathrm{a}$ & $5,17 \mathrm{a}$ & $6,67 \mathrm{a}$ \\
Testemunha (água) & - & $3,67 \mathrm{a}$ & $7,33 \mathrm{a}$ & $7,83 \mathrm{a}$ \\
\hline
\end{tabular}

*Notas de 1 a 9 , onde: 1 = planta sadia e $9=$ planta morta.

**Medias seguidas de mesmas letras minúscula na coluna ou maiúscula na linha, não diferem estatisticamente entre si, pelo teste de Tukey a 5\% de probabilidade.

A microbiolização de sementes de feijoeiro com $P$. aglomerans, R. leguminosarum (7), B. subtilis (11), B. cereus e P. fluorescens (4) mostrou viabilidade no controle da murcha-de-curtobacterium em condições controladas, pela diminuição da severidade dos sintomas da doença nas plantas, seja pelas ações antagônicas a Cff (7) ou pela indução de mecanismos de resistência na planta (11).

A não eficácia do controle da murcha-de-curtobacterium pelos isolados de Fusarium spp. pode ser explicada hipoteticamente pela não produção de metabólitos tóxicos no cultivo líquido ou pela não absorção desses metabólitos via raízes no substrato contido nos vasos. Caso esses metabólitos fossem produzidos, seriam translocados no xilema e interfeririam na colonização da Cff e na indução dos mecanismos de resistência nas plantas. Outra possibilidade diz respeito ao método de inoculação de Cff com punção de agulha infectada no caule das plantas, pois embora esse método tenha sido empregado com sucesso por Corrêa et al. (4), nos trabalhos de Huang et al (7) e Martins et al. (11) a inoculação nas sementes foi o método escolhido como o mais adequado.

Conforme Andrews (1), muitos antagonistas que foram eficientes in vitro não mostram essa mesma eficácia em condições naturais. A variações das condições do ambientes é um grande problema a ser considerado, principalmente em testes a campo.

\section{REFERÊNCIAS}

1. Andrews, J.H. Strategies for selecting antagonistics microrganisms from the phylloplane. In: Windels, C.L.; Lindon, S.E. Biological control on the phylloplane. St. Paul: The American Phytopathological Society, 1985. p.31-44.

2. Bacon, C.W.; Hinton, D.M.; Porter, J.K.; Glenn, A.E.; Kuldau, G. Fusaric acid, a Fusarium verticillioides metabolite, antagonistic to the endophytic biocontrol bacterium Bacillus mojavensis. Canadian Journal of Botany, Ottawa, v.82, p.878-885, 2004.

3. Baker, R.A.; Tatum, J.H.; Nemec J.R.S. Antimicrobial activity of naphthoquinones from fusaria. Mycopathologia, Den Haag, v.111, n.1, p. 9-15, 1990.

4. Corrêa, B.O.; Schafer, J.T.; Moura, A.B. Spectrum of biocontrol bacteria to control leaf, root and vascular diseases of dry bean. Biological Control, Orlando, v.72, p.71-75, 2014.

5. Drysdale, R. The production and significance in phytopathology of toxins produced by species of Fusarium. In: Moss, M.O.; Smith, J.E. (Ed.). The Applied Mycology of Fungi. Cambrigde: Cambridge University Press, 1984. p.95-106.

6. Frosheiser, F.I.; Barnes, D.K. Field reaction of artificially inoculated alfafa populations to the fusarium and bacterial wilt pathogens alone and in combination. Phytopathology, St. Paul, v.68, p.943-946, 1978.

7. Huang, H.C.; Erickson, R.S.; Hisieh, T.F. Control of bacterial wilt of bean (Curtobacterium flaccumfaciens pv. flaccumfaciens) by seed treatment with Rhizobium leguminosarum. Crop Protection, Guildford, v.26, p.1055-1061, 2007.

8. Itô, T. Fusariomicin C, a new cytotoxic substance produced by Fusarium moniliforme. Agricultural and Biological Chemistry, Tokyo, v.43, n.6, 1237-1242, 1979.

9. Johnson, L.E.B.; Frosheiser, F.I., Wilcoxson, R.D. Interaction between Fusarium oysporum $f$. sp. medicaginis and Corynebacterium insidiosum in alfafa. Phytopathology, St. Paul, v.72, n.5, p.517-522, 1982.

10. Maringoni, A.C. Comportamento de cultivares de feijoeiro comum a murchade-curtobacterium. Fitopatologia Brasileira, Brasília, v.7, p.157-162, 2002.

11. Martins, S.J.; Medeiros, F.H.V.; Souza, R.M.; Resende, M.L.V.; Ribeiro Junior, P.M. Biological control of bacterial wilt of common bean by plant growth-promoting rhizobacteria. Biological Control, Orlando, v.65, p.65-71, 2013.

12. McLean, M. The phytotoxicity of Fusarium metabolites: an update since 1989. Mycopathologia, Den Haag, v.133, p.163-179, 1996.

13. Menezes, M.; Silva-Hanlin, D.M.W. Guia prático de fungos fitopatogênicos. Recife: UFRPE Imprensa Universitária, 1997. 106p.

14. Rasekhi, F.; Tajick, M.A.; Rahimian, H.; Sharifimehr, S. Some phytotoxic and antimicrobial compounds extracted from culture filtrates of Fusarium proliferatum FP85. Journal of Biodiversity and Environmental Sciences, Dhaka, v.4, n.5, p.245-251, 2014.

15. Tayung, K.; Barik, B.P.; Jha, D.K.; Deka, D.C. Identification and characterization of antimicrobial metabolite from an endophytic fungus, Fusarium solani isolated from bark of Himalayan yew. Mycosphere, Guiyang, v.2, n.3, p.203-213, 2011.

16. Valentini, G.; Guidolin, J.N.; Baldissera, J.N.C.; Coimbra, J.L.M. Curtobacterium flaccumfaciens pv. flaccumfaciens: etiologia, detecção e medidas de controle. Biotemas, Florianópolis, v.23, n.4, p.1-8, 2010. 